\title{
HABERMAS E DUCROT: PERCURSOS DA ÉTICA DO DISCURSO
}

\begin{abstract}
Júnia Diniz Focasi
Resumo: Os conceitos de argumentação e de polifonia, desenvolvidos por Ducrot, são interpretados como um modo de ação social. É nesse eixo que a discussão empreendida pelo autor insere a ética discursiva filosófica no âmbito dos estudos do discurso, tão fundamental no mundo moderno. A descrição dos interlocutores, o locutor enquanto tal $L$ e o locutor enquanto ser do mundo $\lambda$ demarcam as posições enunciativas com seus respectivos estatutos sociais e morais. Tal princípio teórico fundamentará a constituição do ethos performativo, relativo ao locutor enquanto ser do mundo $\lambda$ e ao locutor enquanto tal $L$, ambos constituintes do que definiremos como ethos ético, delimitados, respectivamente, no Princípio Universal (U) e no Discurso Prático (D), na terminologia de Habermas. Assim, será o Princípio de Universalização $(U)$ que justifica as pretensões de retitude dos Discursos Práticos e reformula a dimensão objetiva para uma realidade intersubjetiva.
\end{abstract}

Palavras-chave: Polifonia. Ética do Discurso. Ethos.

\begin{abstract}
The concepts of argument and polyphony, developed by Ducrot, are interpreted as a form of social action. It is in this axis that the discussion undertaken by the author inserts the philosophical discourse ethics in the context of discourse studies, so important in the modern world. The description of the interlocutors, the speaker as such $L$ and the speaker as being in the world $\lambda$ demarcate the enunciative positions with their respective social and moral laws. This theoretical principle grounds the constitution of the performative ethos, in relation to the speaker as being of world $\lambda$ and the speaker as such $L$, both constituents of what we define as ethical ethos, delimited, respectively, by the Universal Principle $(U)$ and the Practical Discourse (D), in Habermas's terminology. Thus, it will be the Universal Principle (U) that justifies the straightness of the Practical Discourse claims and that recasts the objective dimension to an intersubjective reality.
\end{abstract}

Keywords: Polyphony. Discourse Ethics. Ethos.

\footnotetext{
' Doutora em Linguística pela Universidade Estadual de Campinas (UNICAMP) e Professora Adjunta da Universidade Federal de Minas Gerais (UFMG) e membro do Programa de Pós-Graduação em Estudos Linguísticos da UFMG. E-mail: junia.diniz@globo.com.
} 
EID\&A - Revista Eletrônica de Estudos Integrados em Discurso e Argumentação, Ilhéus, n. 12, jul/dez.2016.

\section{Introdução}

Vários modelos de descrição semântica, formulados nas últimas décadas, baseiam-se, principalmente, na objetividade da razão lógica. Aludindo-se a Saussure e, posteriormente, a Chomsky e à Gramática Transformacional, Ducrot (1987a) propõe uma alternativa ao modelo teórico da descrição semântica: a paradigmática associada à sintagmática. No conjunto da descrição linguística que desenvolve, conclui o autor que ambas as descrições convergem em um conjunto de regras que permitem prever o efeito das manifestações discursivas. O foco da questão não se restringe apenas à descrição de um item semântico isolado ou de seu significado em uma ordem sintática, mas sim ao seu funcionamento no discurso.

Sob tal perspectiva, Ducrot conclui que o modelo de descrição semântica, baseado na palavra ou em seu contexto sintático, é insuficiente para conferir uma descrição consistente ao fenômeno linguístico, portanto, devendo-se considerar ainda condições pragmáticas relativas aos processos discursivos. Apesar de circunscrever-se a princípios teóricos distintos, Ducrot (1987a, p. 64-65) também assinala não ser possível dissociar língua e fala, esclarecendo que "nossa tese é que a língua (como objeto teórico) deve conter uma referência àquilo que para Saussure corresponde a fala. O que significa dizer, no final das contas, que a distinção metodológica deve ser projetada sobre o dado segundo um traçado diferente daquele proposto por Saussure".

No âmbito de um pensamento distinto, Habermas (1989) também acentua a necessidade da interpretação pragmática das formas linguísticas, analisadas sob o ponto de vista das descrições formais da Linguística. Quanto a isto, Habermas, tal como Ducrot, observa a deficiência do Estruturalismo no que concerne às descrições que se abstraem da Pragmática, já que não se podem prever as estruturas geradas pelos sujeitos da linguagem e sua consequente capacidade de ação, acarretando uma separação entre a língua como um sistema de regras e a dimensão pragmática de seu emprego. A este respeito, Habermas (1989, p. 304) conclui: "a separação dos níveis analíticos 'língua' e 'fala' não devem operar-se de modo que a dimensão pragmática da linguagem fique relegada a uma análise exclusivamente empírica”.

Seguindo o fio desse raciocínio, Habermas esclarece que, embora a esfera do normativo restrinja-se aos parâmetros de validade, esses não são idênticos aos parâmetros de validade assertórica, comum às proposicões 
EID\&A - Revista Eletrônica de Estudos Integrados em Discurso e Argumentação, Ilhéus, n. 12, jul/dez.2016.

lógicas, referentes ao mundo objetivo, visto que as proposições ditas enunciativas se distinguem das proposições predicativas ou lógicas. Neste sentido, as proposições enunciativas explicitam-se através dos atos de fala, ao passo que as proposições lógicas não apresentam o mesmo estatuto, não sendo passíveis, portanto, de serem falseadas ou negadas.

Na obra Teoria da Ação Comunicativa, Habermas postula os princípios racionais universais que regulam as interações comunicativas, utilizando-se do conceito de competência linguística de Chomsky, reconstrutiva das condições universais para a produção de enunciados, ou de proposições enunciativas. Assim, ele explana sua opção pelo modelo chomskiano:

\begin{abstract}
A hipótese maduracionista de Chomsky de que a teoria da gramática representa exatamente as disposições inatas que capacitam a criança a desenvolver as hipóteses que comandam a aquisição da linguagem e elaborar os dados linguísticos que recebe do contexto parece-me que é demasiado forte. No âmbito da estratégia conceptual reconstrutivista, é suficiente a hipótese mais plausível de que a teoria da gramática representa a competência linguística do falante adulto (HABERMAS, 1989, p. 319).
\end{abstract}

$\mathrm{Na}$ visão habermasiana, os proferimentos linguísticos conectam-se, necessariamente, a condições universais de validez e, desse modo, validam as pressuposições universais e necessárias ao entendimento linguístico. No mesmo diapasão de Chomsky, a experiência organiza-se em uma rede conceitual a que Habermas (1989, p. 321) denomina de transcendental, assim explicitada: "Chamamos 'transcendental' a estrutura conceptual que se repete em todas as experiências coerentes, enquanto não caia refutada a afirmação de sua necessidade e universalidade".

Assim, o filósofo opera a reconstrução racional dos processos comunicativos. Se a linguagem, tal como o postula Chomsky, é inerente ao ser humano, a sua essência interliga-se aos universais linguísticos, portanto também extensiva aos processos de comunicação, traço distintivo do ser humano. Logo, pressupõe-se que as competências prático-comunicativas sejam um conhecimento universal e, concomitantemente, competências universais dos falantes, constituindo o a priori das condições de emprego da linguagem e de sua natureza social. Nestes termos, uma teoria da competência comunicativa é o ponto de partida para uma Pragmática Universal, fundamentando um conceito mais amplo de racionalidade embasada em uma análise formal da linguagem, não circunscrita apenas ao conteúdo semântico. 
EID\&A - Revista Eletrônica de Estudos Integrados em Discurso e Argumentação, Ilhéus, n. 12, jul/dez.2016.

A consequência imediata desse princípio teórico reside no fato de que o saber linguístico constitui uma competência comunicativa articulada por intermédio de pretensões de validez internas aos proferimentos linguísticos No contexto da competência comunicativa, Habermas acrescenta o conceito de situação ideal de fala que, conforme Siebeneichler (1989, p. 105), "pode ser tomada como critério da argumentação discursiva porque implica uma distribuição simétrica de chances de escolha e de realização de atos de fala. Supomos que nela não existe nenhum elemento de coação a não ser a coação do melhor argumento". Desse modo, a lógica da argumentacão infere que a situacão ideal de fala parta do pressuposto necessário à comunicação e que se converta em um ideal da realidade linguística. A articulação desse modelo de teorização semântico-pragmático concentra-se nas normas sociais que coordenam a Ação Comunicativa e o discurso racional baseado no entendimento mútuo. Complementando essa teorização, são os pressupostos pragmáticos da argumentação e do discurso que coordenam a explicitação das pretensões de validez dos enunciados linguísticos que, em uma situação abstrata e ideal de fala, estipulam normas de validez universais, ou seja, no princípio pragmático-transcendental de pressupostos universais de argumentação.

A Pragmática Universal reconstrói as ações comunicativas reguladas por normas sociais ao mesmo tempo em que toma como pano de fundo o mundo da vida, do qual os falantes não podem se eximir, apoiando-se em razões discursivamente estipuladas através dos atos de fala. Tal postulado delimitará o percurso teórico e metodológico na discussão aqui empreendida, pois procede à articulação de duas vertentes teóricas distintas, porém imbricadas no que diz respeito à argumentação e à discursividade. A Pragmática, em certa medida, é o conceito que amalgama os discursos em suas situações cotidianas, revestidos na expressão de uma fundamentação ética que a eles subjaz.

Assim sendo, o conceito de racionalidade comunicativa vem respaldado pelas pretensões de validez suscetíveis de crítica de acordo com padrões morais e éticos de responsabilidade dos indivíduos incluídos no intercâmbio linguístico. Portanto, segundo Habermas, a questão da Ética do Discurso está circunscrita ao fato de que as pretensões de validez, estipuladas pelos atos de fala, estão interligadas a normas de ação, manifestando um consenso racionalmente motivado. 
EID\&A - Revista Eletrônica de Estudos Integrados em Discurso e Argumentação, Ilhéus, n. 12, jul/dez.2016.

Questões como as das posições ocupadas pelos sujeitos no âmbito de uma Ética do Discurso expressam a performatividade como princípio de argumentação que se manifesta por intermédio dos contornos éticos do discurso, na interação entre discurso e mundo social. Nesse aspecto, salientamos aqui que o nosso propósito se concentra no pensamento de Habermas, na Ética do Discurso e nas formas de argumentação nas quais prevalece o entendimento mútuo. Entendimento que discutiremos, nas articulações do discurso, enquanto forma constitutiva de um ethos ético, de uma performatividade que ecoa a voz ética do discurso social, também refletido no pensamento de Ducrot, principalmente em seus aspectos polifônicos e discursivos.

Em Analyses Pragmatiques, Ducrot (1980a) constata que a delimitação dos dois personagens fundamentais ao discurso - locutor e destinatário - não é suficiente para se determinar uma descrição detalhada do sentido de um enunciado, identificando separadamente os personagens do ato ilocucional (enunciadores e destinatários) e os personagens da enunciação (locutor e alocutário). A diferença entre esses dois grupos de interlocutores reside no fato de que o enunciador é identificado como um personagem diferente daquele que reivindica a responsabilidade da enunciação - o locutor havendo uma divergência entre os personagens da enunciação e os do ato ilocucional.

No cerne da delimitação dos sujeitos do discurso, Ducrot considera que o valor argumentativo de um enunciado permanece inscrito nas frases, contudo as intenções argumentativas enlaçam uma relação direta com os personagens da enunciação. Nesses termos, a interpretação polifônica do sentido de um enunciado reforça ainda mais as relações argumentativas, já que é definida agora como uma relação entre interlocutores.

Em linhas gerais, Ducrot postula que a Pragmática deve estar associada à Semântica, integrando-se aos processos de enunciação dos enunciados, segundo Benveniste (1958), como atos sui-referenciais. Percurso semelhante, mas por vias diversas, é percorrido por Habermas ao postular a Pragmática Universal, relativa às condições universais do entendimento possível, fundamentada nos pressupostos universais da Ação Comunicativa.

Considerando, também, a linguagem como fenômeno social, Austin (1962) demonstra que há, na linguagem, uma infinidade de enunciados que só podem ser descritos no momento discursivo, pois representam modos 
EID\&A - Revista Eletrônica de Estudos Integrados em Discurso e Argumentação, Ilhéus, n. 12, jul/dez.2016.

específicos de ação - os performativos. Na sua doutrina, a linguagem é processo, ação que se manifesta através dos locutores. O ponto central de sua obra está na delimitação dos enunciados performativos, a consideração dos atos ilocucionais e, finalmente, a postulação de uma teoria geral dos atos de fala.

Ducrot, ao formular a Pragmática Linguística, explicita ser ela relativa à ação humana e ao emprego da linguagem, afirmando que "não se trata mais do que se faz quando se fala, mas do que se considera que a fala, segundo o próprio enunciado, faz". A este processo ele denomina como efeito da enunciação, "sendo necessário descrever sistematicamente as imagens da enunciação que são veiculadas pelo enunciado" (DUCROT,1987b, p. 163-164)

Embora com formulações teóricas e epistemológicas distintas, pode-se articular o pensamento filosófico de Habermas às análises desenvolvidas por Ducrot, principalmente, na teorização que articula para a Semântica na qual distingue os dois níveis de análise que levam em consideração o seu funcionamento no discurso.

Assim, as ideias de Benveniste sobre a subjetividade na linguagem, 0 trabalho de Austin sobre os performativos e os atos ilocucionais determinam o papel dos interlocutores como agentes ativos na produção do sentido. Este emana do momento discursivo, situando-os enquanto indivíduos engajados no processo de interação linguística e social. Benveniste (1958) coloca a subjetividade como elemento agenciador da linguagem, introduzindo, na Linguística, a prevalência da subjetividade. A linguagem é interpretada como o espaço dialético e histórico no qual se expressa a relação subjetiva entre o eu e o tu, derivado da reciprocidade que os particulariza mutuamente. Ela é, antes de tudo, o domínio do homem. É nela e através dela que ele se manifesta enquanto ente psíquico e social, revelado através da palavra.

\section{As vozes da Ética do Discurso: Polifonia}

Os conceitos de argumentação e de polifonia desenvolvidos por Ducrot, definidos por ele como uma Pragmática Linguística ou Pragmática Semântica, são interpretados, nessa perspectiva da linguagem, como um modo de ação social. É neste ponto que a discussão até aqui empreendida insere a ética discursiva filosófica no âmbito dos estudos do discurso. Ou como nos ensina Habermas (2007, p. 31): “A escolha do esquema interpretativo pode se 
EID\&A - Revista Eletrônica de Estudos Integrados em Discurso e Argumentação, Ilhéus, n. 12, jul/dez.2016.

justificar não somente pelos dados empíricos (se a teoria 'funciona' ou não), mas também pela verificação dos próprios instrumentos teóricos".

A teoria polifônica institui, no domínio da enunciação, dois tipos de locutores: um deles corresponde ao ser responsável pelo discurso, quem se responsabiliza por sua realização é o locutor enquanto tal L. O segundo é o locutor enquanto ser do mundo $\lambda$. Há, portanto, um enunciador cuja perspectiva é o ponto de vista do qual se enuncia. Partindo desse ponto de vista, delimitaremos aqui o conceito de ethos, balizado pelas análises de Ducrot, corroboradas no pensamento de Habermas no que concerne a um ethos performativo (o locutor $\lambda$ no Discurso Prático (D)) encarnado no discurso público que amplifica a voz de um compromisso ético, de uma ética discursiva.

A fim de fundamentar a distinção entre esses dois interlocutores, Ducrot (1987b) exemplifica com a Retórica ao afirmar que a imagem de si é constituída pelo orador, o locutor enquanto tal $L$; já aquilo que se expressa relativamente "enquanto objeto da enunciação" diz respeito ao locutor enquanto ser do mundo $\lambda$. Portanto, Ducrot delimita os limites entre o falante autor do enunciado e aquele que profere enunciações polifônicas e argumentativas.

Portanto, a estrutura argumentativa de fundamentação racional da moral divide-se em duas premissas essenciais: o Princípio de Universalização (U) como regra de argumentação para Discursos Práticos (D), e o princípio da perspectiva universal do Princípio de Universalização (U) calcado nos pressupostos pragmático-universais da argumentação.

Ao discutir a essência do termo Ética do Discurso, Habermas relaciona-a às questões morais, éticas e pragmáticas, constituindo aspectos diferentes da razão prática. As histórias de vida, as expectativas ou os desejos individualizados estão entrelaçadas ao contexto das identidades coletivas, sociais e históricas. A esse respeito, Habermas explica:

Já a formação da vontade individual rege-se, de acordo com sua ideia, por uma argumentação pública, que se limita a reproduzir in foro interno. Onde a moral embate nos limites da moralidade, o que está em causa não é, portanto, uma mudança de perspectiva da interioridade do pensamento monológico para a publicidade do discurso, mas uma modificação na colocação do problema: o que se modifica é o papel em que o outro sujeito se apresenta (HABERMAS, 2014, p. 335). 
EID\&A - Revista Eletrônica de Estudos Integrados em Discurso e Argumentação, Ilhéus, n. 12, jul/dez.2016.

No intuito de estabelecer uma correlação entre Ducrot e o pensamento filosófico aqui estabelecido, podemos afirmar que Ducrot se aproxima das conceituações filosóficas aqui levantadas e discutidas. Há de se notar a definição de enunciação, baseada no fato de que constitui "um acontecimento constituído pelo aparecimento de um enunciado", sendo ela também um "acontecimento histórico", destituída da noção "de um sujeito autor da fala e dos atos de fala". Conclui Ducrot ao afirmar: "Mas acontece que tenho necessidade, para construir uma teoria do sentido, uma teoria do que é comunicado, de um conceito de enunciação que não encerre em si, desde o início, noção de sujeito falante" (DUCROT, 1987b, p. 169).

Ao desenvolver suas argumentações teóricas, Ducrot distingue significação e sentido, atribuindo-lhes, respectivamente, o conceito semântico de frase e de enunciado, sendo a diferença entre eles de estatuto metodológico, ou seja, a explicação do sentido opera-se via o fato de que o enunciado possa ter uma determinada interpretação, de onde decorre a negação de que o significado possa fazer parte do sentido. Assim sendo, o sentido do enunciado está direcionado para o que, na enunciação, está estabelecido como um ato jurídico, algo que deve ser interpretado através de indicações sobre a enunciação. Sobre esta afirmação Ducrot assinala:

O sentido do enunciado é uma representação da enunciação de indicar outros aspectos desta representação. Dizer que um enunciado possui, segundo os termos da filosofia da linguagem, uma força ilocutória, é para mim dizer que ele atribui a sua enunciação um poder "jurídico", o de obrigar a agir (no caso de uma promessa ou uma ordem), o de obrigar a falar (no caso da pergunta), o de tornar lícito o que não era (no caso da permissão), etc. (DUCROT, 1987b, p. 172).

Quanto a isso, é pertinente observar que o poder jurídico ao qual Ducrot alude está interligado ao aspecto moral e ético da enunciação linguística. Tal como concebido por Habermas, o ato jurídico impõe aos interlocutores uma obrigação ética e moral no que se refere ao que está expresso no ato de fala. Talvez por essa razão Ducrot rejeite o ilocucional do ato de fala. Assim, indiretamente, o autor confirma o nosso percurso interpretativo ao indicar que o falante não introduz no sentido um ato ilocucional, mas marca no enunciado descrições de sentidos que se comunicam ao interlocutor, sendo elas pragmáticas pelo fato de que, através dos atos de fala, transmitem um saber relativo à própria enunciação. Ducrot ressalta esse raciocínio ao afirmar que "interpretar uma produção linguística consiste, entre outras coisas, em reconhecer nela atos, e que este reconhecimento se faz atribuindo ao 
EID\&A - Revista Eletrônica de Estudos Integrados em Discurso e Argumentação, Ilhéus, n. 12, jul/dez.2016.

enunciado um sentido, que é o conjunto de indicações sobre a enunciação" (DUCROT, 1987b, p. 173).

É no cerne deste conjunto de indicações sobre a enunciação que se situa a delimitação entre o que o enunciado efetivamente pode dizer e o seu estatuto de comunicar algo que não seja apenas o de se exprimir uma determinada condição de discurso empiricamente condicionada. Ao estipular semelhante estatuto ao ato de fala, Ducrot converge para a delimitação dos processos argumentativos no discurso, expressando que "a argumentação, com efeito, muito diferente do esforço de persuasão, é para mim um ato público, aberto, não pode realizar-se sem se denunciar enquanto tal" (DUCROT, 1987b, p. 174).

No texto Ilocutionaire et Performatif, Ducrot estabeleceu como personagens do discurso o locutor, o destinatário e o ouvinte, sendo este último quem apenas presencia o discurso que se realiza. Na sua exposição, o destinatário é sempre ouvinte, mas o ouvinte pode não ser o destinatário, fato que se impõe por sua função que é a de ser para quem se coloca uma situação jurídica. Nesse quadro discursivo, o efeito jurídico produzido pelo ato ilocucional é decorrência do sentido do enunciado, sentido este que se manifesta através da enunciação. Em suma, o sentido do enunciado comporta uma alusão à sua enunciação, constituindo seu valor ilocucional uma caracterização jurídica do mesmo.

Assim, o enunciado é único, mas seu sentido é determinado pela enunciação que o veicula. Portanto, se, na enunciação, a sua força ilocucional for a de produzir um efeito de sentido como, por exemplo, uma promessa, o seu sentido constitui o fato de que algo foi prometido. Neste aspecto, voltamos à discussão anterior na qual discutimos a questão da tematização dos atos de fala, sendo assim modalizados por uma determinada pretensão de validez interpessoalmente reconhecida, segundo Habermas.

Para Ducrot, o enunciado corresponde à força ilocucional, ao passo que, na enunciação, se estabelece como fonte do sentido, um poder jurídico. É nessa perspectiva que o sentido de um enunciado deve comportar uma alusão à sua enunciação, pois não poderíamos afirmar que um enunciado seja uma promessa se a sua enunciação não o qualificou como tal. Assim, interpretar um enunciado é ler uma descrição de sua enunciação. Com relação a essa questão, é importante assinalar que a qualificação da enunciação está condicionada à função dos interlocutores no discurso. 
EID\&A - Revista Eletrônica de Estudos Integrados em Discurso e Argumentação, Ilhéus, n. 12, jul/dez.2016.

Inserido em um postulado semelhante, Habermas (1989) destaca que a força ilocucional dos atos de fala produz, entre os interlocutores, uma relação interpessoal condicionada a uma força vinculante de normas reconhecidas de ação. Assim, se o ato de fala implica uma ação, consequentemente, atualiza um padrão de validez reciprocamente reconhecido como normativo, cujos papéis sociais e formas de vida culturais e sociais são descritos por Ducrot como um ato jurídico.

Neste aspecto, a racionalidade discursiva interpõe-se como uma relação interpessoal que estipula pretensões de validez já tematizadas, determinando uma forma de comunicação. Assim sendo, os atos de fala estipulam um sentido modal específico gerador das relações interpessoais. Em certo sentido, vemos uma confluência, embora com pontos de vista metodológicos distintos, entre o pensamento de Habermas e o de Ducrot, visto que a consideração dos enunciados como fonte da enunciação e de seu consequente valor jurídico impõe aos falantes certas obrigações que podemos qualificar aqui como normativas. No mesmo contexto, Ducrot nos diz:

O sentido do enunciado é simplesmente que a enunciação obriga... Quando um sujeito falante faz um ato ilocutório, o que ele faz saber ao interlocutor é que sua enunciação tem tal ou tal virtude jurídica, mas que não a apresente como tendo esta virtude. $O$ semanticista que descreve o que o sujeito falante diz de sua enunciação no enunciado, não pode, pois, introduzir em suas descrições do sentido a indicação de um ato ilocutório, mas uma caracterização da enunciação vinculada ao enunciado, e que leva a compreender porque o sujeito falante pode efetivamente, ao produzir o enunciado, realizar o ato. Vê-se, por isso, porque chamo "pragmáticas" minhas descrições do sentido dizendo que o sentido é algo que se comunica ao interlocutor: estas descrições são pragmáticas na medida em que levam em conta o fato de que o sujeito falante realiza atos, mas realiza estes atos transmitindo ao interlocutor um saber - que é um saber sobre sua própria enunciação (DUCROT, 1987b, p.173)

A transcrição dessa extensa citação faz-se necessária, visto que nela se encontra o eixo que se vincula ao pensamento de Habermas, a partir do qual poderemos articular uma interpretação calcada na questão da Ética do Discurso. Na verdade, Ducrot não rejeita o ilocucional de forma categórica, mas se utiliza desse conceito para exatamente ampliar os horizontes da ação que se efetiva pelos atos de fala e pela performatividade. Ao reivindicar que a força ilocucional se encontra marcada no enunciado e que a sua enunciação institui um poder jurídico, Ducrot quer nos dizer que é na enunciação que a força da obrigação se manifesta. Dito de outra maneira, poderíamos interpretar essa teorização especificando que a enunciação constitui o lugar 
EID\&A - Revista Eletrônica de Estudos Integrados em Discurso e Argumentação, Ilhéus, n. 12, jul/dez.2016.

dos sujeitos do discurso e que é nela que se estabelecem os vínculos de reconhecimento recíproco entre interlocutores e onde se estabelecem as pretensões de validez passíveis de se expressar no intercâmbio linguístico.

Por este ponto de vista, o enunciado adquire uma dimensão peculiar visto que reverte ao seu estatuto lógico de um ato locucional enquanto um ato proposicional, daí a coerência de Ducrot ao negar ao enunciado o estatuto de ato ilocucional. Contextualizando tal raciocínio, reproduzimos aqui a análise efetuada por Ducrot referente aos sentidos do verbo dizer. Segundo o autor, os possíveis sentidos do verbo dizer implicam o de asseverar ( Dizer $_{1}$ ) e o de mostrar ( $\left(\right.$ Dizer $\left._{2}\right)$, respectivamente, relativos às condicões de verdade/falsidade, portanto a uma lógica proposicional e relativo ao comentário do enunciado sobre a enunciação. Neste sentido, no Dizer 2 , o enunciado mostra o estatuto de um enunciador responsável pela enunciação de um ato de fala. $O$ interessante nessa análise é o fato de que o locutor de um enunciado incorpora um autor virtual atribuído a sua enunciação, e, assim, o enunciado proferido mostra um Dizer $_{2}$ no qual o enunciador necessariamente não se assimila ao locutor, entendido como o autor real, o falante, produtor do enunciado.

$\mathrm{Na}$ verdade, Ducrot estipula a condição de que o Dizer ${ }_{1}$ (asseverar) se refere ao conteúdo proposicional do enunciado, como ele mesmo diz: "uma asserção somente apresenta a enunciação como engajando o seu autor com relação à verdade da proposição asseverada, mas não como prova desta verdade" (DUCROT, 1987b, p. 142). Desse modo, a prova da verdade diz respeito exatamente ao fato de que o que pode ser considerado normativo, válido em relação a uma proposição asseverada, constitui-se em um Dizer $_{2}$ no qual o mostrar remete para condições enunciativas marcadas por pretensões de validez estipuladas como pano de fundo normativo nas interações discursivas.

No mesmo fio condutor de pensamento, Habermas efetua uma análise que se aproxima da de Ducrot, pois, segundo o filósofo, as pretensões de validez dos enunciados, implícitos nos atos de fala, estão relacionados ao uso interativo da linguagem, bem como a pretensão de verdade está implícita no conteúdo proposicional do enunciado. Assim, Habermas considera:

A força ilocucional dos atos de fala que gera entre os participantes uma relação interpessoal está vinculada a uma força vinculante de normas reconhecidas de ação ou de avaliação, na medida em que o ato de fala é uma ação, atualiza um padrão de relação já estabelecida. Se pressupõe sempre a validez de um padrão 
EID\&A - Revista Eletrônica de Estudos Integrados em Discurso e Argumentação, Ilhéus, n. 12, jul/dez.2016.

normativo de instituições, papéis sociais, formas socio-culturais de vida, convenções (HABERMAS, 1989, p. 354)

Conclui Habermas que as pretensões de validez normativas estão universalmente estruturadas nos atos de fala como uma pretensão de verdade, ao passo que, no emprego interpessoal da linguagem, o pano de fundo normativo do ato de fala, os conteúdos proposicionais assumem a forma explícita de enunciações, tematicamente assinaladas por distintas formas de validez veiculadas nos atos de fala, correlatas ao Dizer $_{2}$ em Ducrot.

Segundo Habermas, o emprego da linguagem explicita-se por uma estrutura proposicional veiculada por atos de fala, ou seja, a racionalidade de uma manifestação linguística interliga-se ao fato de que, ao se proferir $p$, o falante levanta a pretensão de validez de que o enunciado seja aceito ou rejeitado, ou seja, passível de crítica pelo interlocutor. Assim, atribuir uma base de validez para os atos de fala equivale a resgatar a dimensão de racionalidade do proferimento linguístico ao mesmo tempo em que estipula uma dimensão de realidade e de racionalidade para o ato de fala em todo o seu espectro.

Neste aspecto, a atitude performativa dos interlocutores, no processo de interação discursiva, assegura a unidade aos mundos tematizados, tendo em vista o entendimento e a auto-reflexão. Uma teoria do agir comunicativo estipula, então, as condições possíveis do entendimento linguístico abarcado pela Pragmática Universal, explicativa dos fundamentos racionais dos processos de entendimento. Nestes termos, o ato de fala explicita a subjetividade, passando a linguagem a delimitar os campos das relações sociais e a exercer uma função participativa, baseada no entendimento linguístico.

No que toca esta questão, Habermas explicita que o conceito de Ação Comunicativa, baseado no entendimento, refere-se a situações restritas, pois será o reconhecimento das pretensões de validez dos enunciados linguísticos que estipula a referência para o que é dito, e, assim, os processos discursivos de entendimento linguístico estão inseridos em um contexto social mais amplo, relativo a diversas instâncias sociais, sendo que uma delas pode ser tematizada nas interações recíprocas entre falantes.

Aqui, o conceito de polifonia aparece como o elemento amalgamador entre a verdade da proposição e o que ela é passível de veicular na esfera social do mundo compartilhado pelos interlocutores. Desse modo, a polifonia estabelece um mostrar que retumba vozes sociais que enunciam uma razão discursiva. Em outros termos, os conteúdos normativos, universalmente 
EID\&A - Revista Eletrônica de Estudos Integrados em Discurso e Argumentação, Ilhéus, n. 12, jul/dez.2016.

reconhecidos, são colocados em discussão no contexto das enunciações polifônicas delimitadoras de uma racionalidade discursiva, expressa exatamente no processo de interação verbal e interpessoal e onde as pretensões de validez são resgatadas no âmbito do mundo da vida que Ihes atribui a sua condição de uma ação imbuída de responsabilidade moral, imposta por um pano de fundo normativo.

Será no contexto da autoridade polifônica que delimitaremos as duas instâncias do conceito de ethos, sendo, portanto, o ethos performativo aquele que se expressa na racionalidade discursiva implícita na polifonia e cujas pretensões de validez resgatam o conteúdo normativo moral universal (Dizer ${ }_{1}{ }^{-}$ Asseverar), mas que também reverbera o pano de fundo normativo, delimitador de um determinado mundo da vida socialmente compartilhado. A polifonia amplifica a voz e o discurso do sujeito ético que se posiciona ante os conflitos sociais e neles mostra um dizer que se só pode amplificar na dimensão pública do discurso, o ethos ético. Daí, podemos retomar o posicionamento de Habermas a respeito da Norma Universal (U) e do Discurso Prático (D) que reverbera as normas integradas a uma pretensão de validez.

Assim, será o Princípio de Universalização (U) que justifica as pretensões de retitude dos Discursos Práticos e que reformula a dimensão objetiva para uma realidade intersubjetiva, o Discurso Prático (D). Desse modo, explica-se o Princípio de Universalização $(U)$ como um princípio ponte, visto que, no pensamento habermasiano, a fundamentação de princípios morais deve estar circunscrita às argumentações e aos processos de entendimento. As pretensões de validez, estipuladas normativamente no discurso, devem estar vinculadas a princípios morais, equacionados consensualmente pelos indivíduos envolvidos no processo discursivo. Por este ângulo de visão, o discurso ético opera-se no âmbito de um processo dialógico entre interlocutores no qual o Princípio Universal $(U)$ deve ser aceito por todos os demais envolvidos no diálogo, fundamentando assim a derivação de uma Ética discursiva. Portanto, a verdade deve ser justificada em um discurso teórico, Princípio Universal (U) e as enunciações em um Discurso Prático (D).

Segundo Habermas, a distinção entre moral e ética está balizada por três empregos da razão: a prática (também emprego pragmático), o emprego ético e o emprego moral. A ação assume, portanto, uma racionalidade que se encarna na esfera social, desvinculada da individualização do ser que age em interesse próprio. Habermas resume esta questão ao afirmar que "uma 
EID\&A - Revista Eletrônica de Estudos Integrados em Discurso e Argumentação, Ilhéus, n. 12, jul/dez.2016.

unidade somente é perceptível na multiplicidade de suas vozes" (HABERMAS, 1990, p. 153). Em sentido semelhante, Ducrot (1987b, p.174) estabelece o conceito de argumentação, por ele definido como "um ato público e aberto, não pode realizar-se sem se denunciar enquanto tal".

Provavelmente, a pragmática semântica ou linguística de Ducrot converge, guardando-se as devidas proporções, em algumas noções de discurso e de ética discursiva estabelecidas por Habermas, principalmente ao desvincular a noção clássica do ilocucional como sendo apenas critério de convenções e de intenções. Ultrapassando estes limites, Ducrot inscreve o ato de fala na esfera social, na produção dos sentidos que não apenas se balizam nos atos de fala, mas encarnam-se no enunciado historicamente delimitado e de onde provêm as múltiplas enunciações não mais circunscritas ao sujeito falante empírico, mas a uma voz geral (o ON como centro de perspectiva) amplificadora do discurso social. Sob este ponto de vista, a pragmática de Ducrot mantém uma relação profunda com a pragmática filosófica de Habermas já que o conceito de ação linguística implica certas normas a que os sujeitos falantes se submetem no convívio social.

\section{Considerações finais}

Em Analyse de textes et linguistique de l'enonciation, Ducrot (1980b) estabelece o postulado teórico de que se o enunciado descreve sua enunciação, isso implica apresentá-lo como produzido por um locutor. No entanto, a interpretação polifônica de um enunciado baseia-se no fato de que alguém diferente do locutor proferiu algo. Já o conceito de polifonia manifesta-se pela condição de que um falante indeterminado, ou uma voz geral (ON), expressou algum fato. Seu princípio básico é o de que, ao se exprimir a si próprio, exprime-se também o outro. Ocorrem, portanto, duas vozes em um único enunciado.

Partindo da ideia de que o sentido de um enunciado comporta um acúmulo de vozes, do qual uma delas é a do locutor, porém superposta a outras vozes que são a de seus enunciadores virtuais ou imaginários, Ducrot altera a descrição da enunciação estabelecida em trabalhos anteriores. Para ele, o que é fundamentalmente constitutivo do sentido dos enunciados são os traços que o sentido comporta em relação aos eventuais autores da enunciação. Os outros aspectos ilocucionais e argumentativos são secundários em relação às indicações mais primitivas pressupostas por tudo o que se pode 
EID\&A - Revista Eletrônica de Estudos Integrados em Discurso e Argumentação, Ilhéus, n. 12, jul/dez.2016.

dizer sobre os autores do discurso. A descrição da enunciação e de seus aspectos intrínsecos depende, essencialmente, da descrição de seus personagens enquanto figuras que a produzem e a representam.

Ao discutir a essência do termo Ética do Discurso, Habermas relaciona-a às questões morais, éticas e pragmáticas, constituindo aspectos diferentes da razão prática. As histórias de vida, as expectativas ou os desejos individualizados estão entrelaçadas ao contexto das identidades coletivas, sociais e históricas.

Os planos performativo e proposicional atribuem uma realidade ao logos humano enquanto ser-no-mundo, instauradores de uma relação intersubjetiva que torna possível a relação reflexiva do homem sobre si mesmo e a sua identificação como sujeito.

A dimensão filosófica da relação linguagem e mundo social e o postulado fundamental de uma Ética do Discurso, balizada por uma Pragmática Transcendental, determina a linguagem como ponto de convergência do sujeito do discurso e das condições racionais e comunicacionais das validades intersubjetivas dos proferimentos linguísticos. Nestes termos, a questão da verdade ou da falsidade das proposições é objeto da consciência humana que pode lhes atribuir uma pretensão de validez ou ainda as pretensões humanas à verdade. Neste plano, essas pretensões explicitam-se na performatividade, nas condições pragmáticas que fundamentam a Ética do Discurso.

No que concerne à interação entre Filosofia e Discurso, podemos agora explicitar melhor em que parâmetros consideramos essa necessária comunhão entre as duas vertentes de pensamento, integradas uma a outra, mas, paradoxalmente, distanciadas, não pela sua epistemologia, mas por uma questão de método e de práticas. A fundamentação filosófica de uma Ética do Discurso traz para o interior das práticas linguísticas o conflito moral que tanto exacerba a consciência do homem moderno. Os dilemas cruciais que envolvem a moral e a ética, reverberados em uma sociedade globalizada, devem deslocarse de sua dimensão filosófica para penetrar no universo do discurso.

\section{Referências}

AUSTIN, John Langshaw. Quando dizer é fazer. Palavras e ação. Porto Alegre: Artes Médicas, 1990 [1962]. 
BENVENISTE, Émile. Da subjetividade na linguagem. Princípios de Linguística Geral 1. Campinas: Pontes, 2005 [1958].

DUCROT, Oswald. Estruturalismo, Enunciação e Semântica. In: 0 dizer e o dito. Campinas: Pontes, 1987a. p. 63-88.

DUCROT, Oswald. Esboço de uma teoria polifônica da enunciação. In: 0 dizer e o dito. Campinas, Pontes, 1987b. p. 161-218.

DUCROT, Oswald. Illocutoire et performatif. In : Dire et ne pás dire. Paris, Hermann Éditeurs, 1991. p. 279-305.

DUCROT, Oswald. Analyses pragmatiques. Communications, Paris, n. 32, $1980 a$.

DUCROT, Oswald. Analyses de textes et linguistique de l'énonciation. In: Les mots Du discours. Paris, Minuit, 1980b. p. 07-56.

HABERMAS, Jürgen. Teoría de la acción comunicativa. V. I e Il. Madrid, Taurus, 1988.

HABERMAS, Jürgen. Teoría de La Acción Comunicativa: complementos y estúdios prévios. Madrid, Cátedra, 1989.

HABERMAS, Jürgen. A unidade da razão na multiplicidade de suas vozes. In: Pensamento Pós-Metafísico. Estudos Filosóficos. Rio de Janeiro, Tempo Brasileiro, 1990. p. 151-182.

HABERMAS, Jürgen. A Ética da discussão e a questão da verdade. São Paulo, Martins Fontes, 2007.

HABERMAS, Jürgen. Sobre o uso pragmático, ético e moral da razão prática. In: Ética do Discurso, Lisboa, Edições 70, 2014. p. 316-337.

SIEBENEICHLER, Flávio Beno. Jürgen Habermas: Razão comunicativa e emancipação. Rio de Janeiro: Tempo Brasileiro, 1989.

Forma de citação sugerida:

FOCAS, Júnia Diniz. Habermas e Ducrot: percursos da ética do discurso. EID\&A Revista Eletrônica de Estudos Integrados em Discurso e Argumentação, Ilhéus, n. 12, p. 119-134, jul/dez.2016.

Recebido em: 24/08/2016

Aprovado em: 04/12/2016 